The National Ignition Facility and the Promise of Inertial Fusion Energy

E. I. Moses

December 16, 2010

19th Topical Meeting on the Technology of Fusion Energy Las Vegas, NV, United States

November 7, 2010 through November 11, 2010 
This document was prepared as an account of work sponsored by an agency of the United States government. Neither the United States government nor Lawrence Livermore National Security, LLC, nor any of their employees makes any warranty, expressed or implied, or assumes any legal liability or responsibility for the accuracy, completeness, or usefulness of any information, apparatus, product, or process disclosed, or represents that its use would not infringe privately owned rights. Reference herein to any specific commercial product, process, or service by trade name, trademark, manufacturer, or otherwise does not necessarily constitute or imply its endorsement, recommendation, or favoring by the United States government or Lawrence Livermore National Security, LLC. The views and opinions of authors expressed herein do not necessarily state or reflect those of the United States government or Lawrence Livermore National Security, LLC, and shall not be used for advertising or product endorsement purposes. 


\title{
THE NATIONAL IGNITION FACILITY AND THE PROMISE OF INERTIAL FUSION ENERGY
}

\author{
E. I. Moses \\ Lawrence Livermore National Laboratory, Livermore, CA, U.S.A.94450 \\ E-mail; moses1@,llnl.gov
}

The National Ignition Facility (NIF) at the Lawrence Livermore National Laboratory (LLNL) in Livermore, $C A$, is now operational. The NIF is the world's most energetic laser system capable of producing $1.8 \mathrm{MJ}$ and $500 \mathrm{TW}$ of ultraviolet light. By concentrating the energy from its 192 extremely energetic laser beams into a $\mathrm{mm}^{3}$ sized target, NIF can produce temperatures above 100 million $K$, densities of $1,000 \mathrm{~g} / \mathrm{cm}^{3}$, and pressures 100 billion times atmospheric pressure-conditions that have never been created in a laboratory and emulate those in planetary interiors and stellar environments. On September 29, 2010, the first integrated ignition experiment was conducted, demonstrating the successful coordination of the laser, cryogenic target system, array of diagnostics and infrastructure required for ignition demonstration. In light of this strong progress, the U.S. and international communities are examining the implication of NIF ignition for inertial fusion energy (IFE). A laser-based IFE power plant will require a repetition rate of $10-20 \mathrm{~Hz}$ and a laser with $10 \%$ electrical-optical efficiency, as well as further development and advances in large-scale target fabrication, target injection, and other supporting technologies. These capabilities could lead to a prototype IFE demonstration plant in the 10- to 15-year time frame. LLNL, in partnership with other institutions, is developing a Laser Inertial Fusion Engine (LIFE) concept and examining in detail various technology choices, as well as the advantages of both pure fusion and fusion-fission schemes. This paper will describe the unprecedented experimental capabilities of the NIF and the results achieved so far on the path toward ignition. The paper will conclude with a discussion about the need to build on the progress on NIF to develop an implementable and effective plan to achieve the promise of LIFE as a source of carbon-free energy.

\section{INTRODUCTION}

The National Ignition Facility (NIF) is the U.S. Department of Energy (DOE) and National Nuclear Security Administration (NNSA) center to study inertial confinement fusion (ICF) and high energy density (HED) science. ${ }^{1}$ NIF is the largest scientific project ever successfully completed by the DOE. The 192-beam football stadium-sized NIF was certified as complete in March 2009 and is now fully operational and conducting experiments at Lawrence Livermore National Laboratory
(LLNL). A total 192-beam energy of 1.1 MJ $3 \omega$ was demonstrated on March 10, 2009, over 30 times more energy than ever produced in an ICF laser system. Completing the NIF was a monumental task. NIF was recently recognized for its excellence in project management and was awarded the prestigious Project Management Institute's (PMI's) 2010 Project of the Year. PMI cited NIF's groundbreaking technical achievement and exemplary management in its award decision.

NIF's 192 beams are directed into a 10-meterdiameter vacuum target chamber containing a $\sim 1$-cm-long cylindrical hohlraum target. The NIF target chamber contains entry ports for all the laser beams and over 100 ports for diagnostic instrumentation and target insertion. Sophisticated diagnostic instruments such as x-ray and neutron spectrometers, $\mathrm{x}$-ray imagers, and streak cameras are mounted around the equator and at the poles of the target chamber. ${ }^{2,3,4}$ Fig. 1 below shows a cut-away drawing of the NIF with 192 beams arranged into two laser bays, as well as the 10-meter-diameter target chamber.

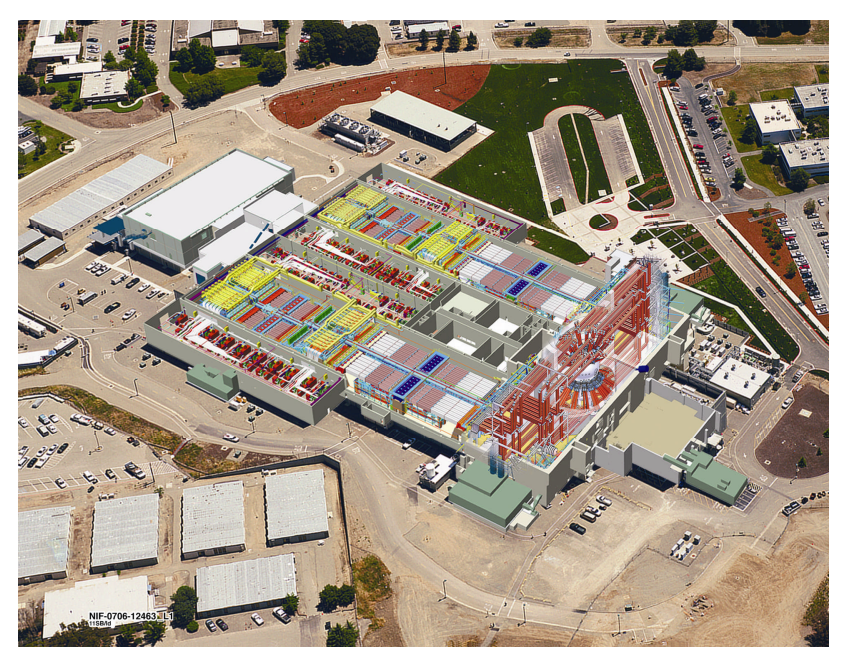

Fig. 1. The National Ignition Facility cutaway drawing.

NIF uses solid-state, neodymium glass amplifiers pumped by the energy from flashlamps. The lasers deliver about $5 \mathrm{MJ}$ of infrared laser energy in a few-nanosecond pulse. The laser pulse is sent through the amplifiers several times by an optical switch to maximize the energy extracted and improve the system efficiency. 
Before reaching the target chamber, the energetic beams are reflected off mirrors to arrange their entry into the spherical chamber from all sides. Just before entering the chamber, the beams pass through optical frequency multipliers to convert the infrared laser light to ultraviolet. This conversion to a shorter wavelength enhances the efficiency of the interaction with the fuel-bearing target. As the large beams enter the chamber, they are each focused onto a very small spot size on the target at the chamber center. The beams hit the target with a precision of better than 50 microns (about the thickness of a piece of paper).

The laser interaction within the hohlraum produces a radiation field with temperatures of several hundred $\mathrm{eV}^{5,6}$ NIF is designed to achieve target temperatures of 100 million $\mathrm{K}$, radiation temperature over 3.5 million $\mathrm{K}$, density of $1,000 \mathrm{~g} / \mathrm{cm}^{3}$ and 100 billion times atmospheric pressure. These conditions have never been created before in a laboratory and exist naturally only in astrophysical environments. The resulting hohlraum conditions will provide the environment to explore a wide range of high energy density science experiments, including laboratoryscale thermonuclear ignition and burn.

NIF is the largest optical instrument ever constructed, with over 38,000 large and small optics and 60,000 points controlled by two million lines of software. The NIF $3 \omega$ energy specification of $1.8 \mathrm{MJ}$ requires an order of magnitude increase in operating fluence over previous laser systems. Developing high-quality optics that can withstand the NIF environment has been a major research and development focus at LLNL. A systematic and robust approach for optics finishing and maintenance has been developed to support the demanding requirements for fusion ignition.

\section{THE NATIONAL IGNITION CAMPAIGN}

The NIF ignition program is being executed via the National Ignition Campaign (NIC), a national effort that includes General Atomics (GA), LLNL, Los Alamos National (LANL) and Sandia National Laboratories (SNL), the University of Rochester Laboratory for Laser Energetics (LLE), and a number of other collaborators including Lawrence Berkeley National Laboratory, the Massachusetts Institute of Technology, the U.K. Atomic Weapons Establishment (AWE), and the French Atomic Energy Commission (CEA). ${ }^{7}$ The NIC has two major goals: (1) begin integrated ignition experiments with cryogenic, layered ignition targets in late 2010, and (2) demonstrate a reliable and repeatable ignition platform by the conclusion of NIC at the end of FY2012. The scope for NIC includes the ignition physics program as well as the development of the diagnostics, targets, target cryogenic system, phase plates and other optics, and personnel and environmental protection activities required to execute ignition experiments. The NIC will also develop the infrastructure and processes required to operate NIF as a national user facility. ${ }^{7}$

NIF ignition experiments use a centimeter-scale hohlraum containing a 2-millimeter-scale, thin-walled plastic or beryllium capsule filled with a mixture of deuterium and tritium ${ }^{8}$ (see Fig. 2). Compression of the capsule by a $>280-\mathrm{eV}$ radiation field inside the ignition hohlraum drives the DT fuel to conditions under which it will ignite and burn, liberating more energy than is required to initiate the fusion reaction. ${ }^{9}$

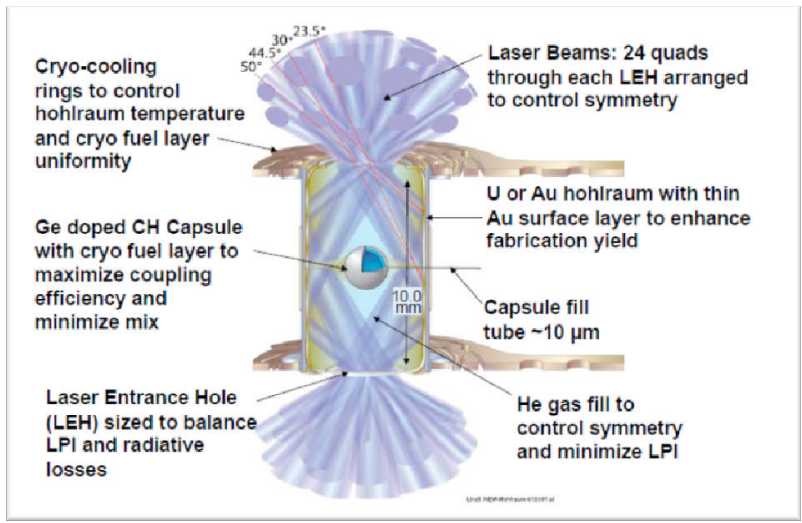

Fig. 2. A schematic diagram of an ignition point design target.

The campaign to initially demonstrate NIF ignition is proceeding in four phases. In the first or "drive" step, the empty hohlraum is tuned to produce the necessary radiation drive on the capsule as a function of time. In the second step, "capsule tuning," a variety of non-cryogenic and cryogenic capsules are used to adjust the hohlraum symmetry, shock timing, velocity and mass ablated to produce the conditions in the imploding capsule required for ignition when a cryogenic fuel layer is incorporated. The third step consists of layered cryogenic implosions conducted with a nominal $72 \% / 22 \% / 6 \%$ mixture of tritium, hydrogen, and deuterium (THD), respectively. The reduced yields from these THD targets allow the full diagnostic suite to be employed and the presence of the required pre-burn temperature and fuel areal density to be verified. The final step is DT ignition implosions with expected gains of 10-20. The initial DT ignition experiments will be conducted with $\mathrm{E}_{\text {laser }} \sim 1.3 \mathrm{MJ}$. Laser energies of up to $1.8 \mathrm{MJ}$ will be available for subsequent experiments.

In the fall of 2009, experiments conducted in support of the NIC focused on the first two steps discussed above. These initial experiments were aimed at understanding the energetics of the NIF ignition hohlraum and initial capsule-tuning experiments. The results from these initial 
experiments have been outstanding and show great promise for achievement of ignition. ${ }^{10}$

Capsule implosion experiments at energies up to 1.3 MJ have demonstrated laser energy absorption, radiation temperatures, and symmetry control that scale to ignition conditions. Of particular importance is the demonstration of peak hohlraum temperatures over $300 \mathrm{eV}$, with overall backscatter of less than $10 \%$ and the ability to field cryogenic targets with tunable $\mathrm{x}$-ray drive symmetry. ${ }^{11}$

Fig. 3 shows images of the cryo-layered target before and after it was shot on September 29, 2010, on the NIF. This was the first integrated ignition experiment on NIF and the first in a series that will lead up to conducting full-scale ignition experiments. This experiment, using a THD capsule, demonstrated the successful coordination of the laser, the cryogenic target system, the array of diagnostics and the infrastructure required for ignition demonstration. Preliminary results of this integrated experiment were very encouraging. All 192-laser beams fired over $1 \mathrm{MJ}$ of laser energy into the hohlraum, and all systems operated successfully with 26 target diagnostics acquiring data. The radiation drive was consistent with earlier shots at this energy $(\sim 290 \mathrm{eV})$, and the preliminary yield estimate was $10^{13}$ neutrons.
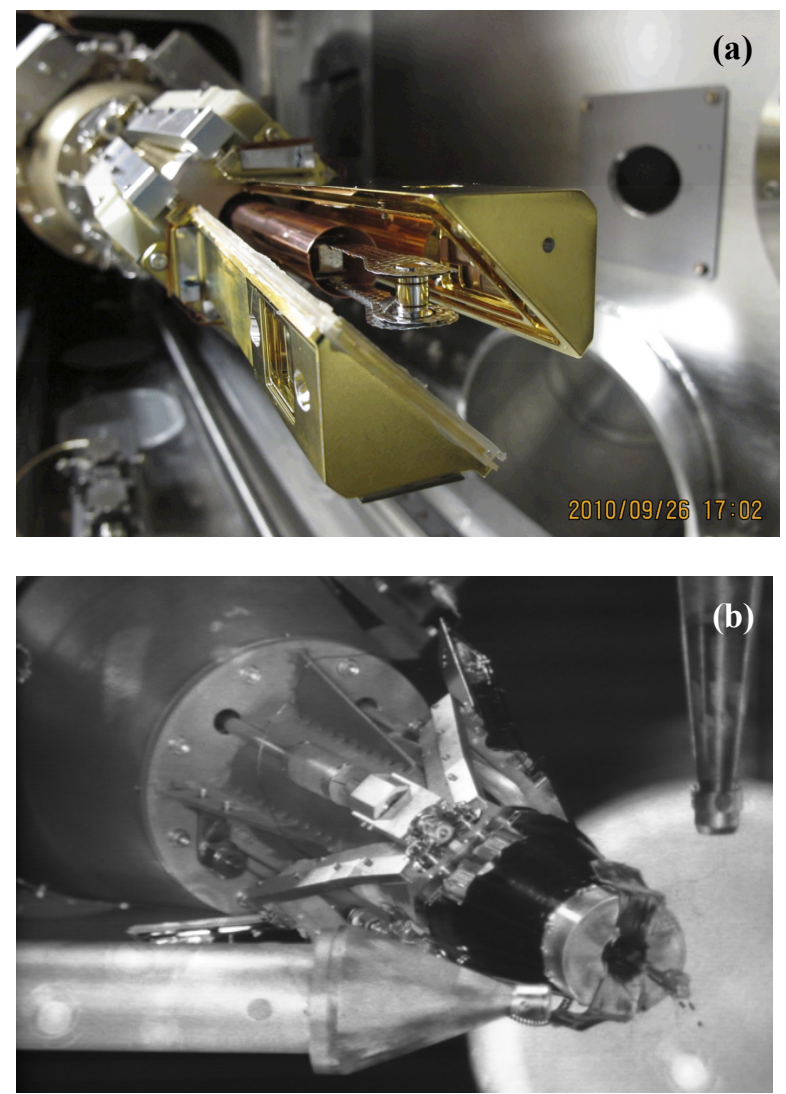

(b)

Fig. 3. Cryogenic layered target shot on September 29, 2010 (a) before and (b) after being shot in the NIF target chamber.
Recently, NIF has set the record for neutron yield and laser energy on target. On October 31, 2010, the NIC team conducted its third neutron diagnostics calibration shot, firing 121 kilojoules of $3 \omega$ (ultraviolet) light to a deuterium/tritium gas-filled exploding pusher target in polar drive mode. The shot produced a neutron yield of $3 \times 10^{14}$, the highest neutron yield ever accomplished by a laser facility. On November 2, 2010, the NIC team successfully fired $1.3 \mathrm{MJ}$ of $3 \omega$ into a cryogenic hohlraum containing a symmetry capsule (symcap) target. This was the highest-energy laser shot on target ever fired and was the first test of hohlraum temperature and capsule symmetry under conditions designed to produce fusion ignition and energy gain. Preliminary analysis suggests that hohlraum temperatures approached 300 electron volts (about six million degrees Fahrenheit) making this the highest $\mathrm{x}$-ray drive energy ever achieved in an indirectdrive ignition target.

\section{IGNITION PREPARATION PROJECT (IPP)}

Beginning in December 2009, many activities were undertaken at NIF to bring online the capabilities required to conduct a successful ignition campaign. Collectively, these activities are referred to as the Ignition Preparation Project (IPP). These included:

- Systems to support the cryogenic target positioner

- Personnel and Environmental Protection Systems (PEPS) to provide for proper handling of tritium, depleted uranium, beryllium, and nuclear yield

- Target diagnostics systems to support capsule tuning and ignition campaigns

- Robust, efficient operations with increasing levels of routine performance

IPP was officially completed in May 2010, enabling NIF to proceed with ignition experiments.

Cryogenic Target Positioner (CTS). The CTS is a complex system that performs the functions necessary to shoot a cryogenically cooled ignition target at the center of the NIF target chamber, see Fig. 4. The CTS holds the target in place while the capsule is being filled with liquid THD or DT, cryogenically cools the target to form the THD or DT "ice" layer within the capsule, characterizes and maintains the layer quality until the experiment is initiated, inserts and locates the target within the NIF chamber, and removes the protective shroud to expose the target just prior to the arrival of the laser pulse. The CTS was attached to the NIF target chamber and was operationally qualified in August 2010. 


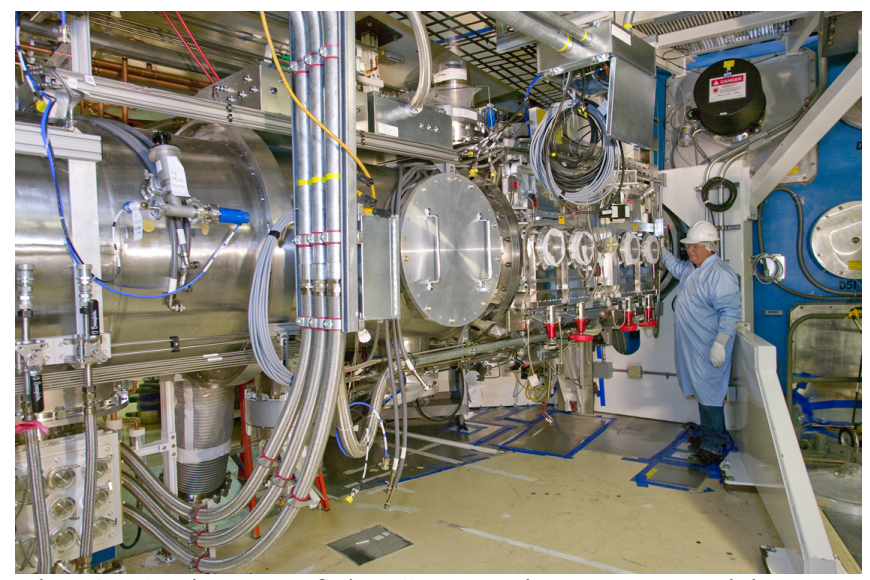

Fig. 4. An image of the Cryogenic Target Positioner installed at the NIF.

Personnel and Environmental Protection Systems. Several PEPS systems were operationally qualified during the IPP including:

- Forty-four shield doors that were assembled, mounted, and filled with concrete; these doors, some weighing as much as five tons, provide neutron and radiation shielding for high-yield ignition experiments in and around the Target Bay

- The Tritium Processing System (TPS) used to remove tritium from the target chamber exhaust streams, shown in Fig. 5

- Radiation Monitoring System to provide continuous monitoring of the radiation environment in the NIF facility

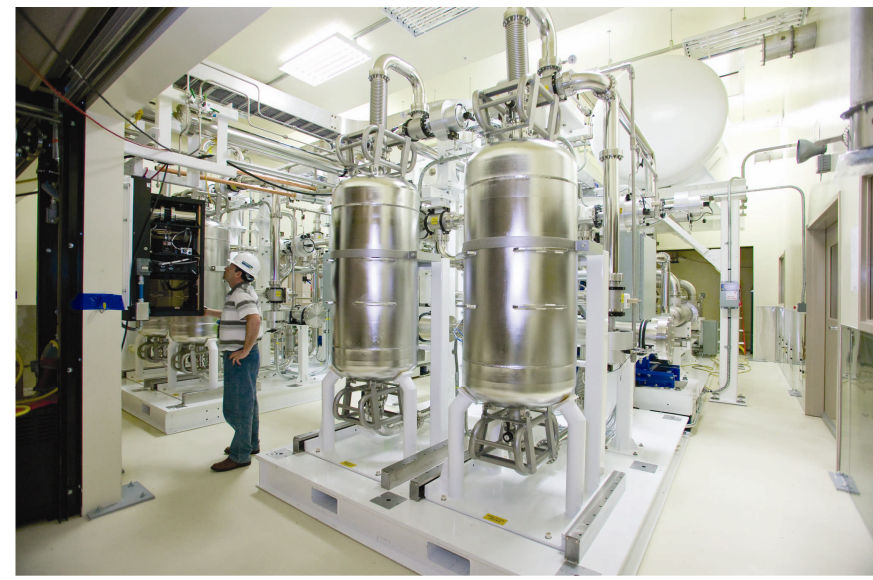

Fig. 5. NIF’s Tritium Processing System.

Target Diagnostics. During FY2010, a large number of new target diagnostics were developed, calibrated, installed and commissioned on the NIF. These include additional hohlraum/capsule diagnostics and an initial set of ignition diagnostics. Examples of the new hohlraum/capsule diagnostics include the Velocity Interferometer System for Any Reflector (VISAR) and
VISAR in combination with Streaked Optical Pyrometry (VISAR/SOP). These diagnostics provide the ability to measure shock timing. Other capabilities such as backlighting and streaked radiography enable measurement of implosion velocity and remaining mass of the imploding capsule wall. The new ignition diagnostics provide the capability to measure important ignition parameters such as neutron yield, ion temperature, areal density, the shape and size of the imploding core, and the absolute burn history in neutron environments. Examples of these diagnostics include neutron activation detectors (NADs), neutron time-offlight detectors (nTOFs), a magnetic recoil spectrometer (MRS), a hardened, gated $\mathrm{x}$-ray imager (h-GXI), a gamma reaction history diagnostic (GRH) and a neutron imager (NI). It is important to note that the NIC diagnostics effort is a major national and international collaborative effort involving the NIC partners (LLNL, LANL, LLE, SNL, and GA), and a large number of collaborations from U.S. institutions and organizations such as MIT, Duke University, Lawrence Berkeley National Laboratory (LBNL), and National Technologies, LLC (NSTec), as well as AWE and CEA. NIF diagnostics development is providing many opportunities for attracting new scientists and collaborations.

Robust and Efficient Operations. During the IPP, plans and procedures for managing tritium, beryllium, depleted uranium and associated activation and fission products were developed and put into place. These flow down from regulatory requirements into practices and protocols. The required administrative controls were implemented through authorizing documents and work permits for specific activities at the NIF. A detailed training and qualification program was also developed to assure that workers understand the hazards and controls associated with their work and are qualified to work safely in the environment at NIF. This included extensive training and qualification.

\section{LASER INERTIAL FUSION ENERGY}

The successful commissioning of the NIF laser, the IPP and the hohlraum energetics results to date represent the first essential steps in producing ICF ignition in the laboratory. The achievement of ignition at NIF will demonstrate the scientific feasibility of ICF and focus the world's attention on the potential of IFE as a source for carbon-free energy.

It is important to note that many of the scientific and technological advances made under NIF in areas such as laser technology, target fabrication, and diagnostics directly support the advancement of IFE. However, a laser-based IFE power plant will require a repetition rate of $10-20 \mathrm{~Hz}$ and approximately $10 \%$ electrical efficiency. 
As such, the realization of IFE will require further development and advances in many areas including mass manufacturing of targets, injection and tracking of inflight targets, and fusion chamber technologies.

The NIF laser architecture itself is a major step forward for IFE. NIF is the first ICF laser to use a multipass design; the validation of this design is essential to the success of both NIF ignition and solid-state laser-based IFE. The current laser designs under consideration for IFE rely on modifications of the NIF architecture, including the replacement of $400-\mathrm{W}$ average power dischargepumped flashlamps with $30-\mathrm{kW}$ average power laser diodes and implementation of He-gas cooling. ${ }^{12}$ The validated NIF laser architecture, the performance of the 10-Hz, 50-J Mercury laser at LLNL and similar systems elsewhere in the world, and new ideas for compressing the physical size of the laser by over an order of magnitude, indicate the potential to achieve the desired performance characteristics for an IFE laser beamline. Alongside this, developments elsewhere in the semiconductor diode industry, including fabrication technology for LED backlit LCD televisions, have reduced the quoted price for bulk manufacture of laser diodes to a point where they would now represent an acceptable fraction of the cost of construction of an IFE plant.

Advances in target fabrication and target diagnostics made by the NIC team also have direct benefit to IFE. The NIC team has developed advanced capsule and hohlraum manufacturing techniques and robust layering methodologies that demonstrate the ability to achieve the demanding requirements on surface roughness, capsule sphericity, layer thickness and fill tube technology. Additionally, the NIC diagnostics effort has spurred research into developing target and laser diagnostic systems capable of survival in the extreme neutron and $\mathrm{x}$ ray environment associated with ignition conditions. This is required to establish a robust, repeatable and sufficiently high-gain platform for IFE applications.

The demonstration of ignition at NIF and the technology development undertaken by the NIC team provide a solid basis for future scientific and technological development in support of IFE. LLNL, in collaboration with many national and international partners, continues to actively pursue the LIFE concept and has now established a self-consistent point design that couples specific driver, target, chamber and other technologies required to implement a 1-GW commercialization in the 2030s, consistent with widespread fusion-based power production in the 2050 time frame. ${ }^{13}$ The requirements-based approach being undertaken is defining the areas in which further research and technology development are required as part of an integrated project to construct a high-repetition-rate IFE demonstration facility. NIC results coupled with a robust LIFE development program would lead to the delivery of this plant in a 10- to 15-year time frame.

Fusion energy holds the promise of an energy source with no greenhouse gas emissions and with a virtually inexhaustible, widely available fuel supply. It would remove the need for actinide enrichment and reprocessing and high-level waste storage. While these and other features of fusion energy are attractive, scientific and technological challenges remain.

\section{CONCLUSIONS}

After many years of $R \& D$, all the pieces for ignition are in place: the NIF laser and the equipment needed for ignition, including high-quality targets and an ignition point-design target. Layered cryogenic targets are now being fielded that combine all the technologies for a fullscale ignition experiment. The National Ignition Campaign is on course to demonstrate a robust and repeatable ignition platform by 2012, marking the culmination of over 50 years of research.

Although significant technical challenges must still be met to incorporate this physics achievement into an IFE power plant, a self-consistent point design for a LIFE plant delivering 1-GW net electricity has been established, along with a development program that would enable a demonstration plant to be constructed in the early 2020s. Rollout of a commercial fleet would then be enabled for initiation in the early 2030 s, with material choices such that the doubling time of the installed capacity should not be limited by material supply.

This work performed under the auspices of the U.S. Department of Energy by Lawrence Livermore National Laboratory under Contract DE-AC52-07NA27344. LLNL-CONF-464130.

\section{REFERENCES}

1. E. I. MOSES, "Overview of the National Ignition Facility," Fusion Science and Technology 54 (2): 361-366 (2008).

2. E. I. MOSES, "Multi-megajoule NIF: Ushering in a new era in high energy density science," Proceedings of SPIE - The International Society for Optical Engineering 7005: art. no. 70050F (2008).

3. E. I. MOSES and W. R. MEIER, "The National Ignition Facility and the golden age of high energy density science," IEEE Transactions on Plasma Science 36 (3): 802-808 (2008).

4. NIF web site, http://www.llnl.gov/nif/ 
5. N.B. MEEZAN, L.J. ATHERTON, D.A.

CALLAHAN, E.L.DEWALD, S. DIXIT, E.G. DZENITIS, M.J. EDWARDS, C.A. HAYNAM, D.E. HINKEL, O.S. JONES, O. LANDEN, R.A. LONDON, P.A. MICHEL, J.D. MOODY, J.L. MILOVICH, M.B. SCHNEIDER, C.A. THOMAS, R.P.J. TOWN, A.L. WARRICK, S.V. WEBER, K. WIDMANN, S.H. GLENZER, L.J. SUTER, B.J. MACGOWAN, J.L. KLINE, G.A. KYRALA, and A. NIKROO, "National Ignition Campaign Hohlraum Energetics,” Phys. Plasmas 17, 056304 (2010).

6. "Precision Diagnostics Tell All," Science \& Technology Review, LLNL, UCRL-TR-52000-10-9, (December 2010).

7. “National Ignition Campaign Execution Plan," LLNL report UCRL-AR-213718, NIF-0111975-AA (June 2005).

8. E. I. MOSES, "Ignition on the National Ignition Facility: a path towards inertial fusion energy," Nucl. Fusion 49, 104022 (2009).

9. J.D. LINDL, "Inertial confinement fusion: the quest for ignition and energy gain using indirect drive," American Institute of Physics Press, New York (1998).
10. S. H. GLENZER et al., "Symmetric Inertial Confinement Fusion Implosions at Ultra-High Laser Energies," Science 327, 1228 (2010).

11. P. MICHEL, L. DIVOL, E. A. WILLIAMS, S. WEBER, C. A. THOMAS, D. A. CALLAHAN, S. W. HAAN, J. D. SALMONSON, S. DIXIT, D. E. HINKEL, M. J. EDWARDS, B. J. MACGOWAN, J. D. LINDL, S. H. GLENZER, and L. J. SUTER, "Tuning the Implosion Symmetry of ICF Targets via Controlled Crossed-Beam Energy Transfer," Phys. Rev. Letters 102, 025004 (2009).

12. A.J. BAYRAMIAN et al., "Fusion Energy: Laser Systems Required to Harness the Power of the Sun," LLNL-CONF-425776, CLEO Fusion Energy Systems (2010).

13. M. DUNNE and E. MOSES et al., "Timely Delivery of Laser Inertial Fusion Energy (LIFE)," 19th Topical Meeting on the Technology of Fusion Energy (TOFE) (2010). 